\title{
Luteolin: A Flavonoid that Has Multiple Cardio-Protective Effects and Its Molecular Mechanisms
}

\author{
Yuanyuan Luo 1,2, Pingping Shang ${ }^{3}$ and Dongye Lit,2,3* \\ ${ }^{1}$ The First Clinical College, Nanjing University of Chinese Medicine, Nanjing, China, ${ }^{2}$ The Affiliated Hospital of Xuzhou \\ Medical University, Xuzhou, China, ${ }^{3}$ Institute of Cardiovascular Disease Research, Xuzhou Medical University, Xuzhou, China
}

\section{OPEN ACCESS}

Edited by:

Issy Laher,

University of British Columbia,

Canada

Reviewed by:

Ayodeji Oyenihi,

Stellenbosch University, South Africa

Giulia Borghetti,

Temple University, United States

Sarah Jane Chapple,

King's College London,

United Kingdom

*Correspondence:

Dongye Li

dongyeli@xzhmu.edu.cn

Specialty section:

This article was submitted to Cardiovascular and Smooth Muscle Pharmacology,

a section of the journal

Frontiers in Pharmacology

Received: 15 July 2017 Accepted: 19 September 2017 Published: 06 October 2017

Citation:

Luo Y, Shang P and Li D (2017) Luteolin: A Flavonoid that Has Multiple Cardio-Protective Effects and Its Molecular Mechanisms.

Front. Pharmacol. 8:692.

doi: 10.3389/fphar.2017.00692
Cardiovascular disease (CVD) has become the leading cause of morbidity and mortality worldwide. A well-monitored diet with a sufficient intake of fruits and vegetables has been confirmed as a primary prevention of CVD. Plant constituents such as flavonoids have been shown to confer healthy benefits. Luteolin (Lut), a kind of flavonoid, possesses anti-oxidative, anti-tumor, and anti-inflammatory properties. Recent scientific literature has reported the cardiac protective effects of Lut in vitro and in vivo. Therefore, the aim of this review is to provide an update and detailed overview with cardioprotective molecular mechanisms of Lut with a focus on multiple intrinsic and extrinsic effectors. We further explore how these mechanisms participate in ischemia/reperfusion (I/R) injury, heart failure (HF) and atherosclerosis (AS). A proper understanding of the cardiovascular protective effects and the relative mechanisms of Lut may provide the possibility of new drug design and development for CVD. With the previous studies mainly focused on basic research, we need to advance the prospects of its further clinical utilization against CVD, large prospective clinical trials of Lut are needed to observe its therapeutic effects on patients with I/R injury, HF and AS, especially on the effective therapeutic dosage, and safety of long-term administration.

Keywords: luteolin, cardio-protection, target effectors, I/R injury, heart failure, atherosclerosis

\section{INTRODUCTION}

Flavonoids are naturally occurring compounds that are universally present in the plant kingdom (Hertog et al., 1992). The basic structure of flavonoids consists of an aromatic A-ring and a heterocyclic C-ring, which are connected with an aromatic B-ring through a carbon-carbon bridge. Based on heterocyclic C-ring variation, flavonoids are divided into six subclasses: flavones, flavonols, flavanones, catechins, or flavanols, anthocyanidins and isoflavones (Weng and Yen, 2012). Data sets from the Australian National Nutrition Survey (10,851 subjects $>18$ years) on flavonoid content of foods showed that the key sources of flavonoids included tea (black and green tea), vegetable (onion, celery, parsley, broccoli, English spinach, bean), fruits (apple, grape, coffee, oranges, lemon, mandarin, cherry, blueberry) and wine (Somerset and Johannot, 2008). Since discovery of flavonoids in 1936, more than 5,000 structures of flavonoids have been reported with a wide range of molecular diversity. The Women's Health Study with 38,408females $\geq 45$ years showed that the median intake of total flavonoids ranging from 8.88 to $47.44 \mathrm{mg}$ /day in 11.5 years follow-up (Wang et al., 2009). The Dutch National Food Consumption Survey indicated that people in Netherlands have an average mixed flavonoids intake of $23 \mathrm{mg} /$ day. Epidemiological evidence shows that intake of these 
compounds does not only inhibit tumor formation and inflammation, but also effectively prevents cardiovascular diseases (CVD). In the Zutphen Elderly Study, Hertog et al. (1993) reported that the intake of flavonoids was inversely related to mortality $(p=0.015)$ and myocardial infarction $(p=0.08)$. Schüssler et al. (1995) reported that main flavonoids from Crataegus species increased coronary flow and relaxation velocity Langendorff heart models. The greatest increases of coronary flow (186\%) and relaxation velocity (104\%) were found in the luteolin-7-glucoside group (Schüssler et al., 1995). Therefore, generous dietary intake of flavonoids may be an effective primary prevention of CVD.

Luteolin $\left(3^{\prime}, 4^{\prime}, 5^{\prime}, 7^{\prime}\right.$-tetrahydroxyflavone, Lut) is one of the most prevalent flavones. Molecular formula of Lut is $\mathrm{C}_{15} \mathrm{H}_{10} \mathrm{O}_{6}$ and the structure is showed in Figure $\mathbf{1}$ (Weng and Yen, 2012). A variety of vegetables, fruits and herbs such as carrot, cabbage, artichoke, tea, celery and apple are rich in Lut. The median intake of Lut is $0.01-0.20 \mathrm{mg} /$ day $(0.0349-0.698 \mu \mathrm{mol} /$ day) (Wang et al., 2009). Lut is absorbed by the intestinal mucosa. After oral administration of $14.3 \mathrm{mg} / \mathrm{kg}$ Lut, the maximum plasma concentration $(\mathrm{Cmax})$ was $1.97 \pm 0.15 \mathrm{~g} / \mathrm{ml}$. The time to reach Cmax was $1.02 \pm 0.22 \mathrm{~h}$ and the half-life of Lut (t1/2) was $4.94 \pm 1.2 \mathrm{~h}$. It was converted to free Lut, glucuronide and sulfate-conjugates of Lut and of $O$-methyl Lut (diosmetin or chrysoeriol) in the plasma of rats. Free Lut is also presentin human plasma (Lopez-Lazaro, 2009). Through intrinsic and extrinsic signaling pathways, Lut is an active compound with anti-oxidant, anti-tumor, anti-inflammatory, and anti-apoptotic activities (Sun et al., 2015; Zhang et al., 2016). Due to its potent anti-tumor and anti-inflammatory flavonoid, earlier studies and clinical trials on Lut had thus focused on cancer and inflammation. Since the 1950 s to date, there has been an increase in the number of reports on the cardiovascular effects of Lut. Marijan-Jankovic (1957), N reported that Lut has effects on the heart and vascular vessels. With current advancements in the understanding of oxidative stress and inflammatory mechanisms of the cardiovascular system, Lut exhibits strong cardiovascular protective activities via complex signal transduction pathways and target effectors. Indeed, high dietary intake of Lut is related to a decreased risk of acute myocardial infarction (Qi et al., 2011; Si et al., 2014). The cardio protection mainly stems from decreased myocardial apoptosis, diminished myocardial infarct size and through enhanced left ventricular ejection fraction (Liao et al., 2011).

It has been proposed that Lut exerts protective effects in a multitude of CVD, including coronary artery disease (CAD), heart failure (HF), and atherosclerosis (AS). Relevant studies on this topic have mainly focused on the target effectors of Lut using in vitro and in vivo models. Here we present an update and detailed overview of the molecular mechanisms that orchestrate in cardiac protection conferred by Lut, mainly on the anti-I/R injury, cardiac function in HF and mechanism of anti-AS.

\section{Anti-I/R Injury Mechanism of Lut in CAD}

Coronary artery disease is a serious problem affecting human health (Moran et al., 2013). The most efficient method used to reduce mortality in these patients is to reperfuse the myocardium by interventional treatment or pharmacological therapy (Cabadés et al., 2010). However, myocardial ischemia/reperfusion (I/R) injury followed by reperfusion can damage the myocardium, inducting reperfusion arrhythmia, no-reflow phenomenon, and systolic/diastolic dysfunction, which affects the outcomes of reperfusion therapy. Therefore, many researchers are seeking more effective drugs that can treat I/R injury in CAD patients. Emerging evidence has revealed that Lut regulates vital effectors involved in the process
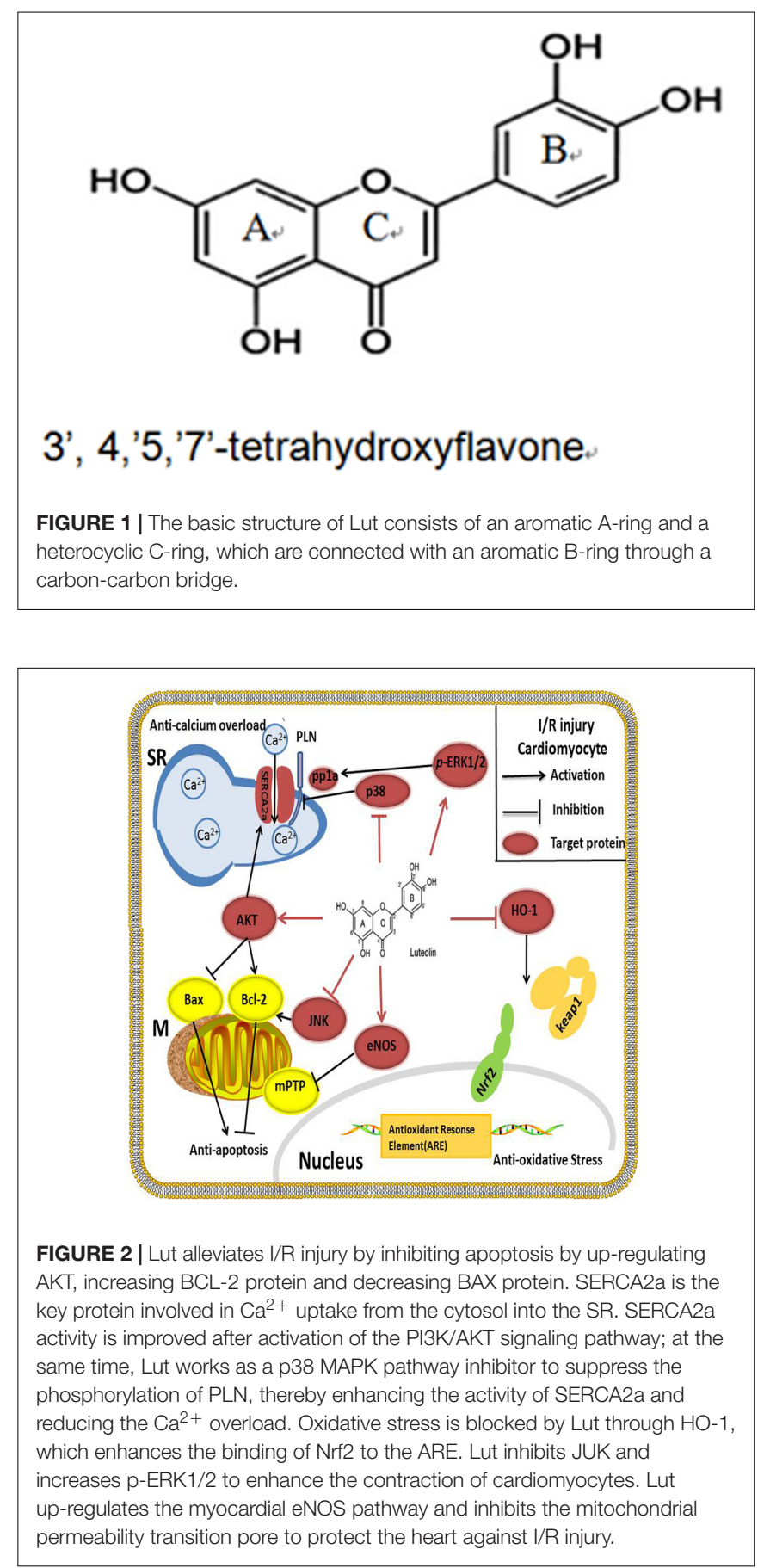
of $\mathrm{I} / \mathrm{R}$ injury and has displayed satisfactory therapeutic value (Figure 2).

\section{Lut Activates Anti-Apoptosis Key Protein AKT}

The phosphoinositide 3-kinase (PI3K)/AKT pathway is a key pathway mediating in cell growth, metabolism and survival (Brazil et al., 2004). AKT has also been confirmed to regulate the apoptotic pathological process of $\mathrm{I} / \mathrm{R}$ injury ( $\mathrm{Ha}$ et al., 2008). In cardiac-protection of Lut against $I / R$ injury, AKT is widely and thoroughly studied: First, Lut suppresses apoptosis by up-regulating AKT in a simulated ischemia/reperfusion (sI/R) model. Pretreatment with Lut significantly inhibited apoptosis, increased BCL-2 expression and the BCL-2/BAX ratio as well as decreased the expression of BAX. Moreover, PI3K inhibitor LY294002 which downregulates AKT expression markedly diminished the function of Lut-induced positive contraction and attenuated the Lut protection against apoptosis in sI/R cardiomyocytes (Fang et al., 2011). Second, previous studies have shown that $\mathrm{Ca}^{2+}$ overload is another major mechanism of myocardial I/R injury. Sarcoplasmic reticulum (SR) $\mathrm{Ca}^{2+}$. ATPase (SERCA2a) is a key protein involved in $\mathrm{Ca}^{2+}$ uptake from the cytosol into the SR and its dysfunction impairs myocardial systolic/diastolic function (Pinton et al., 2008). Our previous study found that Lut improved SERCA2a activity partially through activation of the PI3K/AKT signaling pathway and increased the phosphorylation of AKT (p-Akt) at amino acids 308 and 473 levels, but did not change the SERCA2a expression at protein levels. The infarct size, pro-apoptosis proteins, and lactate dehydrogenase release (LDH) release were reduced by Lut during I/R injury in vivo (Nai et al., 2015), and the same effects were seen in diabetic rats (Sun D. et al., 2012).

\section{Lut Blocks Oxidative Stress through $\mathrm{HO}-1$}

Heme oxygenase-1 (HO-1) is an integral membrane protein located in the smooth endoplasmic reticulum. It is under oxidant-responsive transcription factors NF-E2-related factor 2 (Nrf2) regulation, a pathway that promotes cytoprotection against oxidative stress. When Kelch-like ECH-associated protein 1(Keap1) binds Nrf2, transcriptional activation of Nrf2 is repressed. After exposure to oxidative stress, Nrf2 is released from Keap1 and translocates into nuclei, binding to the antioxidant responsive elements (ARE), which in turn activates Nrf2 target gene HO-1 (Motohashi and Yamamoto, 2004). It appears, therefore, that blocking the oxidative stress through the HO-1 is another possible cytoprotective mechanism by which Lut ameliorates I/R injury. In addition, the anti-oxidative activity of Lut has been confirmed by many researchers. Zhang et al. (2013) reported that Lut is the most effective of the five flavonoids isolated from Ixeris sonchifolia in regulating antioxidant activities. In a middle cerebral artery occlusion-induced ischemia rat model, $4 \mathrm{mg} / \mathrm{kg}$ Lut reduced the infarct area, protected neuronal cells from death and increased neuroprotective effects (Zhang et al., 2013). HO-1 expression was significantly up-regulated by Lut pretreatment. They also found that the neuroprotective and anti-apoptotic effects of Lut were abolished by a selective HO-1 inhibitor, tin protoporphyrin IX
(Kim et al., 2017). To clarify the exact mechanisms of cardiacprotection, Sun G.-B. et al. (2012) used hydrogen peroxide $\left(\mathrm{H}_{2} \mathrm{O}_{2}\right)$-induced cytotoxic model in the $\mathrm{H} 9 \mathrm{c} 2$ cell line to show that Lut provided an adaptive survival response via a mechanism that involved alleviating $\mathrm{H}_{2} \mathrm{O}_{2}$-derived oxidative cytotoxicity by increasing HO-1 expression, enhanced the binding affinity of $\mathrm{Nrf2}$ to the ARE and preventing of apoptosis in H9c2 cells. Taken together, these results indicated the vital role of HO-1 on Lut-induced cardio-protective effects (Sun G.-B. et al., 2012).

\section{Lut Improves Cardiomyocyte Function by Regulating MAPKs Family}

Three members of the mitogen-activated protein kinase (MAPK) family are extracellular signal-regulated kinases (ERKs), C-Jun $\mathrm{N}$ terminal kinase/stress-activated protein kinases (JNK/SAPKs) and p38. Cardiomyocyte function can be regulated by MAPKs after I/R injury. Cheng et al. (2010) reported that Lut reduced the JNK, ERK and p38 protein expression to which prevented apoptosis associated neuronal death in rat primary cortical cultures. Yu et al. (2015) also found Lut inhibited the ROSactivated MAPK pathway in myocardial $\mathrm{I} / \mathrm{R}$ injury. In the cardiovascular system, our research group found that the ERK/PP1a/PLB/SERCA2a and JNK pathways participated in Lut mediated cardiac-protection both in vitro and in vivo after I/R. Lut or JNK inhibitor SP600125 significantly enhanced the contraction of cardiomyocytes, improved cardiac function, reduced infarct size and decreased LDH activity. It was noteworthy that, ERK1/2 was not activated during I/R, and ERK1/2 inhibitor PD98059 had no effect on the above indices. However, Lut pretreatment concomitantly increased the phosphorylation of ERK1/2 (p-ERK1/2) and the protective effects of Lut were abrogated by PD98059 (Wu X. et al., 2013).

The p38 is another downstream effector of the MAPK pathway. It has been demonstrated that inhibition of p38 alleviated cardiomyocytes $\mathrm{I} / \mathrm{R}$ injury and afforded cardiacprotection (Bogoyevitch et al., 1996; Kumphune et al., 2012). Our experiments also showed that p38 expression was increased during I/R process and that Lut decreased it. On the other hand, the p38 MAPK pathway inhibitor SB203580 and Lut inhibited the phosphorylation of PLB ( $p$-PLB), hence increased the activity of SERCA2a, alleviated the calcium overload which promoted the recovery of the mitochondrial membrane potential $(\Delta \psi \mathrm{m})$ and reduced the calcium overload-induced apoptosis in $\mathrm{I} / \mathrm{R}$ injury (Zhu et al., 2017).

\section{Lut Regulates NO and NO Synthases Isozymes to Prevent Injury from Free Radicals}

The isozymes of nitric oxide (NO) synthase have been identified in humans: isozyme I (nNOS) that mainly exist in neuronal and epithelial cells, isozyme II (iNOS) that is primarily found in cytokine-induced cells, and isozyme III (eNOS) that is mainly expressed in endothelial cells. NO and NO synthases isozymes closely interact with superoxide radicals. In rats $\mathrm{I} / \mathrm{R}$ injury model, the cardiac-protective capacity of Lut is partly mediated by down-regulation of $\mathrm{NO}$ production and its antioxidant activities. Liao et al. (2011) detected that pretreatment with Lut decreased the plasma NO levels so as to prevent NO from 
TABLE 1 | Effect and target effectors of Luteolin in coronary artery disease.

\begin{tabular}{|c|c|c|c|c|c|}
\hline \multirow[t]{2}{*}{ Dose } & \multirow[t]{2}{*}{ Model } & \multirow{2}{*}{$\begin{array}{l}\text { Target } \\
\text { effectors }\end{array}$} & \multicolumn{2}{|c|}{ End points } & \multirow[t]{2}{*}{ Reference } \\
\hline & & & Increase & Decrease & \\
\hline \multicolumn{6}{|c|}{ Coronary Artery Disease } \\
\hline $\begin{array}{l}40 \mu \mathrm{mol} / \mathrm{l} \\
8 \mu \mathrm{mol} / \mathrm{l}\end{array}$ & $\begin{array}{l}\text { Landendorff - perfused } \\
\text { rat I/R heart } \\
\text { sl/R cardiomyocytes }\end{array}$ & AKT & $\begin{array}{l}p \text {-Akt, } p \text {-PLB, SERCA2a, Bcl-2, } \\
\text { Bcl-2/Bax ratio, cardiomyocyte } \\
\text { shortening amplitude }\end{array}$ & $\begin{array}{l}\text { Apoptotic rate, Bax, infarct size, LDH } \\
\text { release }\end{array}$ & Fang et al., 2011 \\
\hline 200 mg/kg & Myocardial I/R rat model & AKT & $\begin{array}{l}\text { SERCA2a activity, Akt, p-Akt 308, } \\
\text { and } p \text {-Akt } 473, \mathrm{Bcl}-2\end{array}$ & $\begin{array}{l}\text { I/R-induced myocardial infarct size, } \\
\text { LDH release, apoptosis, Bax, cleaved } \\
\text { caspase-3 }\end{array}$ & Nai et al., 2015 \\
\hline $10 \mu \mathrm{g} / \mathrm{kg}$ & $\begin{array}{l}\text { Myocardial I/R diabetic } \\
\text { rat model }\end{array}$ & AKT & $\begin{array}{l}\text { p-Akt 308, and p-Akt 473, left } \\
\text { ventricular EF, FGFR2 and LIF protein } \\
\text { expression, p-Bad }\end{array}$ & $\begin{array}{l}\text { Myocardial infarct size, LDH release, } \\
\text { incidence of arrhythmia, apoptotic } \\
\text { death, the ratio of Bax to Bcl-2, MPO } \\
\text { expression, (IL-6, TNF-a and IL-1a) }\end{array}$ & Sun D. et al., 2012 \\
\hline $160 \mathrm{mg} / \mathrm{kg}$ & $\begin{array}{l}\text { ISO-induced myocardial } \\
\text { injury model }\end{array}$ & $\mathrm{HO}-1$ & $\begin{array}{l}\text { Electrocardiography, heart } \\
\text { vacuolation, the free radical }\end{array}$ & $\begin{array}{l}\text { Serum cardiac enzymes, apoptosis, } \\
\text { AKT and ERK, }\end{array}$ & Sun G.-B. et al., 2012 \\
\hline $87 \mu \mathrm{mol} / \mathrm{l}$ & $\begin{array}{l}\mathrm{H}_{2} \mathrm{O}_{2} \text {-induced } \\
\text { cytotoxicity model in } \\
\mathrm{H} 9 \mathrm{c} 2 \text { cells }\end{array}$ & & $\begin{array}{l}\text { scavenging and antioxidant potential, } \\
\mathrm{HO}-1 \text {, binding ability of Nrf2 to } \\
\text { antioxidant response element }\end{array}$ & & \\
\hline 70 mg/kg & $\begin{array}{l}\text { Myocardial } \\
\text { ischemia/reperfusion } \\
\text { injury model }\end{array}$ & MAPKs & $\begin{array}{l}\text { Cardiac function, protect } \\
\text { ultrastructure of cardiac muscle cells, } \\
\text { myocardial Ultra structure, ERK } 1 / 2 \text {, }\end{array}$ & $\begin{array}{l}\text { Infarct size, LDH, CK, T-SOD, MDA } \\
\text { release, H9c2 cell apoptosis p-p38 } \\
\text { MAPK/p38 MAPK ratiop-JNK/JNK }\end{array}$ & Yu et al., 2015 \\
\hline $30 \mu \mathrm{mol} / /$ & $\mathrm{H} 9 \mathrm{c} 2 \mathrm{sl} / \mathrm{R}$ & & $\begin{array}{l}\text { Mn-SOD mRNA levels, mitochondrial } \\
\text { membrane potential }\end{array}$ & ratio, p47-phox, HO-1 and HSP27 & \\
\hline $\begin{array}{l}8 \mu \mathrm{mol} / \mathrm{l} \\
40 \mu \mathrm{mol} / /\end{array}$ & $\begin{array}{l}\text { Langendorff perfused } \\
\text { heart } \\
\text { Cardiomyocytes }\end{array}$ & MAPKs & $\begin{array}{l}\text { Contraction of the isolated heart and } \\
\text { cardiomyocytes, p-ERK } 1 / 2, \mathrm{Bcl}-2 \text {, } \\
\text { SERCA2a, } p \text {-PLB }\end{array}$ & $\begin{array}{l}\text { Infarct size and LDH activity, } \\
\text { apoptosis, } p \text {-JNK, Bax, p-PP1a }\end{array}$ & Wu X. et al., 2013 \\
\hline $8 \mu \mathrm{mol} / \mathrm{l}$ & $\begin{array}{l}\text { Simulated I/R } \\
\text { cardiomyocytes }\end{array}$ & MAPKs & $\begin{array}{l}p \text {-PLB, activity of SERCA2a, the } \\
\text { recovery of the } \Delta \psi \mathrm{m}, \mathrm{Bcl}-2 \text { and }\end{array}$ & $\begin{array}{l}\text { Calcium overload, apoptosis, } \\
\text { activation of the p38 MAPK pathway, }\end{array}$ & Zhu et al., 2017 \\
\hline $40 \mu \mathrm{mol} / \mathrm{l}$ & $\begin{array}{l}\text { Langendorff perfused } \\
\text { heart }\end{array}$ & & caspase-3 & Bax and cleaved caspase- 3 & \\
\hline $10 \mu \mathrm{g} / \mathrm{kg}$ & $\begin{array}{l}\text { Myocardial IR injury } \\
\text { model }\end{array}$ & NOs & & $\begin{array}{l}\text { Ventricular tachycardia and } \\
\text { ventricular fibrillation incidence ratio } \\
\text { mortality, myocardial infarct size, LDH } \\
\text { release NO levels }\end{array}$ & Liao et al., 2011 \\
\hline 100 mg/kg & $\begin{array}{l}\text { Streptozotocin induced } \\
\text { diabetic rats IR model }\end{array}$ & NOs & MnSOD, eNOS expression & $\begin{array}{l}\mathrm{LDH} \text { release, } \mathrm{MDA}, \mathrm{Ca}^{2+} \text {-induced } \\
\text { mPTP opening, mitochondrial inner } \\
\text { membrane potential }\end{array}$ & Yang et al., 2014 \\
\hline
\end{tabular}

interacting with superoxide radicals. iNOS mRNA and protein level were down-regulated, but nNOS and eNOS expression levels were not significantly altered. On the contrary, another group found that, in diabetic patients and animals, the NOeNOS pathway was down-regulated, and that Lut protected diabetic hearts against I/R injury by activating the myocardial eNOS pathway including the enhancing manganese superoxide dismutase (MnSOD) activity and inhibiting of mitochondrial permeability transition pore (mPTP) opening (Yang et al., 2014). Despite the fact that eNOS up-regulated MnSOD activity and increased MPTP opening, further studies are needed to elucidate the underlying regulatory mechanism.

As a major complication in the CAD treatment I/R injury, $\mathrm{I} / \mathrm{R}$ injury is associated with high mortality. The evidences reviewed above indicate that Lut is a promising anti-I/R agent that impacts a wide range of proteins that are involved in the protective pathways during I/R injury. It is clear that Lut works on AKT and MAPKs to alleviate cardiomyocyte apoptosis and to improve cardiomyocyte function, respectively. Lut also blocks oxidative stress and prevents injuries arising from free radicals through the HO-1 and NO signaling pathways as illustrated in Table 1. The success of investigations on the mechanisms of $\mathrm{I} / \mathrm{R}$ injury in CAD are based on successful modeling of $\mathrm{I} / \mathrm{R}$ injury in vivo or sI/R in vitro. Previous I/R injury models in rats or mice were constructed by left anterior descending (LAD) ligation. The silk suture slipknot was used to ligate the distal $1 / 3$ of LAD, and then the slipknot was released after $30 \mathrm{~min}$ of ischemia to allow for reperfusion of the myocardium. As an alternative to these classical methods, we opted for endovascular balloon occlusion $(2.5 \times 8 \mathrm{~mm}$ balloon size for mice and $3.5 \times 15 \mathrm{~mm}$ balloon size for rats) to induce I/R models. This outer balloon ligation method is more efficient and cause less damage to the tissue than conventional approaches ( $\mathrm{Hu} \mathrm{F}$. et al., 2016). One limitation of the available studies on I/R models is that many studies were performed on non-cardiac cell lines such as $\mathrm{H}_{\mathrm{C}} 2$ cells and HL-1 cells. These cell lines might not model cardiac cells with high fidelity and hence isolated cardiomyocytes using Langendorff system or enzyme digestion methods may be a more reliable choice to study I/R mechanism. 


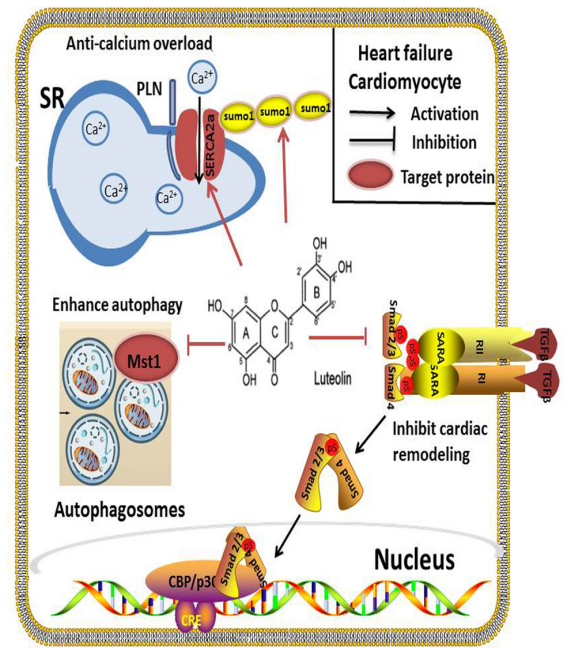

FIGURE 3 | In HF, SERCA2a is a vital target regulated by Lut for effective cardiomyocyte contraction and relaxation. Inhibition of SERCA2a activity markedly abolishes Lut-induced benefits in vitro and in vivo. Autophagy is a self-protection response to stress in HF. Lut up-regulates autophagy through MST1 inhibition, alleviating post-infarction cardiac dysfunction and enhancing autophagic flux in the neonatal cardiomyocytes after hypoxia. Lut protects against cardiac fibrosis and hypertrophy by blocking the Ang II-TGF $\beta 1$ signaling pathway, and suppressing expression of TGF $\beta 1$.

\section{Lut Improves Cardiac Function in HF}

Lut has not only been demonstrated to increase myocardial contractility during I/R injury, but also has received considerable attention from many researchers regarding its long-term application in HF treatment. Wang et al. (2013) reported that long-term Lut treatment of doxorubicin-induced HF in rats was able to improve the cardiac function, in part, by reversing ventricular remodeling. In diabetes mellitusinduced cardiac dysfunction, Lut attenuated myocardial oxidative stress and reversed the reduction of cardiac function (Wang et al., 2012). Studies that have explored the effectiveness and mechanisms of Lut in improving cardiac function in HF have mainly focused on its regulation of cardiomyocytes contractility, enhancement of autophagy in cardiomyocytes and limitation of cardiac remodeling (Figure 3).

\section{Lut Improves Systolic and Diastolic Function of Cardiomyocytes through SERCA2a}

Calcium $\left(\mathrm{Ca}^{2+}\right)$ recycling is a pivotal process for effective cardiomyocyte contraction and relaxation. SERCA2a is an ATPdependent enzyme that regulates $\mathrm{SR} \mathrm{Ca}^{2+}$ stores by pumping $\mathrm{Ca}^{2+}$ into the SR. It is important to modulate cardiac cytosolic $\mathrm{Ca}^{2+}$ levels. Prior investigations have revealed that the expression and activity of SERCA2a were altered in many heart diseases, such as HF and cardiomyopathies. SERCA2a dysfunction causes $\mathrm{Ca}^{2+}$ recycling disorders resulting in severe impairment of cardiomyocyte systolic and diastolic functions (Zsebo et al., 2014; Braunwald, 2015). SERCA2a has become a promising target of pharmacological or gene therapy in HF. Our previous work indicated that Lut improved the contractility of cardiomyocytes by modulatingSERCA $2 \mathrm{a}$ during $\mathrm{I} / \mathrm{R}$ injury. In a $\mathrm{HF}$ rat model, we also found that Lut improved cardiac dysfunction and significantly increased SERCA2a expression, activity and stability, which improved $\mathrm{Ca}^{2+}$ transient and cardiomyocyte contractility. The levels of AKT, phospholamban (PLB), and specificity protein 1 ( $\mathrm{Sp} 1$ ), which are capable of upregulating SERCA2a expression and activity, were also increased in the study (Hu et al., 2017). Based on another study, small ubiquitin-related modifier (SUMO) 1, a post-translationally modified protein that can enhance SERCA2a activity is concurrently increased by Lut (Kho et al., 2011; Tilemann et al., 2013). To confirm the function of SERCA2a in Lut-mediated cardiac protection, inhibition of SERCA2a activity markedly abolished Lut-induced benefits, and inhibition of PI3K/AKT and the MAPKs pathway (ERK, p38) produced the same results ( $\mathrm{Wu}$ X. et al., 2013; Zhu et al., 2017).

\section{Lut Enhances Autophagy by MST 1 Inhibition}

Autophagy is a self-process cell constituents through the lysosomal degradative pathway. This physiological process is essential for protecting cells against excessive or dysfunctional organelles and for maintaining cellular homoeostasis (Takemura et al., 2006). In HF or ischemic cardiomyopathy disease, autophagy acts as a self-protective mechanism in response to stress. Inefficient autophagy leads to poor myocardial performance (Yan et al., 2005; Gustafsson and Gottlieb, 2009). Mammalian sterile 20-like kinase 1 (Mst 1) inhibits autophagy by impairing protein quality control mechanisms in the heart cells. Hu J. et al. (2016) reported that Lut upregulated autophagy through Mst1 inhibition which alleviated post-infarction cardiac dysfunction in the Lut pretreatment group, enhanced autophagic flux, and lessened the aggresomes accumulation in neonatal cardiomyocytes in hypoxia model. Furthermore, in $\mathrm{Mst}^{+/-}$murine model, the protective effects of Lut were abolished (Hu J. et al., 2016). Taken together, the interaction between Lut and Mst1 is a crucial pathway that regulates autophagy in cardiac cells. These findings are important as autophagy is a hallmark of many CVD. Hence, how Lut impacts autophagy at different stages awaits further investigation in order to better exploit its cardiac benefits.

\section{Lut Protects against Cardiac Remodeling by Restoring Ang II-Induced Profibrotic Cytokine TGF $\beta 1$ Expression}

Cardiac remodeling is a pathological process associated with HF. It is characterized by neurohormonal activation, compromised the heart's response to a hemodynamic load and/or injury and alteration to the structure (dimensions, mass, and shape) (Cohn et al., 2000). Cardiac fibrosis and hypertrophy are two types of remodeling patterns, which impair cardiac function and metabolism over time. Oxidative stress has been confirmed as a risk factor for cardiac remodeling (Zhang et al., 2012). Anti-oxidative compounds may have protective effects against cardiac remodeling. Blockade of the Ang II-TGF $\beta 1$ signaling pathway has been demonstrated as 
TABLE 2 | Effect and target effectors of Luteolin in heart failure.

\begin{tabular}{|c|c|c|c|c|c|}
\hline \multirow[t]{2}{*}{ Dose } & \multirow[t]{2}{*}{ Model } & \multirow{2}{*}{$\begin{array}{l}\text { Target } \\
\text { effectors }\end{array}$} & \multicolumn{2}{|c|}{ End points } & \multirow[t]{2}{*}{ Reference } \\
\hline & & & Increase & Decrease & \\
\hline \multicolumn{6}{|l|}{ Heart Failure } \\
\hline $8 \mu \mathrm{mol} / \mathrm{IM}$ & $\begin{array}{l}\text { Abdominal aortic } \\
\text { constriction operation SD } \\
\text { rat model }\end{array}$ & SERCA2a & $\begin{array}{l}\text { Contractility, } \mathrm{Ca}^{2+} \text { transients, } \\
\text { stability of SERCA2a, SUMO 1, Akt, } \\
\text { PLB, Sp1, Bcl-2/Bax, }\end{array}$ & Myocardium fibrosis & Hu et al., 2017 \\
\hline $40 \mu \mathrm{mol} / /$ & $\begin{array}{l}\text { Simulated I/R } \\
\text { cardiomyocytes }\end{array}$ & & caspase-3/cleaved-Caspase3 & & \\
\hline $8 \mu \mathrm{mol} / /$ & $\begin{array}{l}\text { Simulated I/R } \\
\text { cardiomyocytes }\end{array}$ & MAPKs & $\begin{array}{l}p \text {-PLB, activity of SERCA2a, the } \\
\text { recovery of the } \Delta \psi m, B c l-2 \text { and }\end{array}$ & $\begin{array}{l}\text { Calcium overload, apoptosis, } \\
\text { activation of the p38 MAPK }\end{array}$ & Zhu et al., 2017 \\
\hline $40 \mu \mathrm{mol} / \mathrm{l}$ & $\begin{array}{l}\text { Langendorff perfused } \\
\text { heart }\end{array}$ & & caspase-3 & $\begin{array}{l}\text { pathway, Bax and cleaved } \\
\text { caspase-3 }\end{array}$ & \\
\hline $10 \mu \mathrm{g} / \mathrm{kg}$ & $\begin{array}{l}\text { Myocardial infarction } \\
\text { model }\end{array}$ & MST1 & $\begin{array}{l}\text { LVEF, LVFS and ' LV dp/dt max, } \\
\text { Bax/Bcl-2 ratio, GFP-LC3 puncta, } \\
\text { LC3-II and beclin1, mitochondria } \\
\text { function of cardiomyocytes }\end{array}$ & $\begin{array}{l}\text { LVEDD, LVESD, Creatine } \\
\text { kinase-MB, LDH, IL-1a MPO and } \\
\text { TNF-a, cardiomyocytes apoptosis, } \\
\text { caspase-3 activity, accumulation of } \\
\text { aggresomes, P62 Mst1, p-Mst1 }\end{array}$ & Hu J. et al., 2016 \\
\hline $\begin{array}{l}\text { Oral pre- } \\
\text { administration } \\
0.035 \% \\
\text { luteolin }\end{array}$ & $\begin{array}{l}\text { Angiotensin II-induced } \\
\text { hypertension model }\end{array}$ & Ang $\|$ & & $\begin{array}{l}\text { Left ventricular wall thickness, } \\
\text { weight of left ventricular, fibrosis of } \\
\text { the left ventricular wall, } \\
\text { Cardiomyocyte diameter, oxidative }\end{array}$ & Nakayama et al., 2015 \\
\hline $20 \mu \mathrm{mol} / \mathrm{l}$ & $\begin{array}{l}\text { Adult rat cardiac } \\
\text { fibroblasts }\end{array}$ & & & $\begin{array}{l}\text { fluorescence intensity, TGF } \beta 1 \text {, } \\
\text { CTGF, Nox2, Nox4, ANP, and BNP, } \\
p \text {-JNK }\end{array}$ & \\
\hline
\end{tabular}

an effective strategy to prevent cardiac fibrosis in animal models.

Lut has been reported as an anti-fibrotic compound in the lung and liver (Domitrovic' et al., 2009; Chen et al., 2010). The reninangiotensin system (RAS) participates in the pathological process of cardiac remodeling; Ang II is the initial factor of RAS and the pro-fibrotic activator of cardiac fibroblasts (Werner and Böhm, 2008). It stimulates pro-fibrotic cytokine transforming growth factor $\beta$ (TGF $\beta 1$ ) expression (Rosenkranz, 2004). Nakayama et al. (2015) clearly demonstrated that in Ang II-induced hypertension rats, TGF $\beta 1$, CTGF, Nox2, and Nox4 gene expression were increased and oral pretreatment with a high-luteolin diet restored the above indices, and also suppressed $\mathrm{H}_{2} \mathrm{O}_{2}$-induced TGF $\beta 1$ expression. Food-derived Lut may be a therapeutic strategy through the inhibition of Ang II-induced cardiac remodeling (Nakayama et al., 2015).

According to these reports, Lut appears to improve myocardial contractility by increasing the expression and function of SERCA2a, up-regulating autophagy through Mst1 inhibition, and preventing cardiac fibrosis by blocking the Ang II-TGF $\beta 1$ signaling pathway (Table 2). Moremore, different in vitro and in vivo models have been constructed using different Lut working concentrations; the optimal concentration of Lut should be defined by cytotoxic effect test and cell function detection. For example, in isolated ventricular myocytes, the shortening amplitude of single cardiomyocytes was detected after pretreating the myocytes with different Lut concentrations $(4,8,16 \mu \mathrm{M})$. The maximum cell shortening was recorded at the concentration of $8 \mu \mathrm{M}$ and without affecting cellular activities. This concentration of Lut is appropriate for application in isolated ventricular myocytes for HF research.

\section{Anti-Atherosclerosis (AS) Mechanism of Lut}

Atherosclerosis is a chronic inflammatory artery disorder that can affect coronary arteries, the peripheral vasculature, and cerebrovascular structures. Genetic, environmental, psychosocial and pathological factors cause may contribute to the onset of this multi-stage, multi-factorial disease. The pathogenesis of AS comprises lipid accumulation, endothelial dysfunction, cell proliferation and migration, and inflammation (Hansson, 2005). Lut has been demonstrated in many studies to have anti-inflammatory effects, and to inhibit cell proliferation and migration (Cheng et al., 2013; Kritas et al., 2013; Figure 4).

\section{Lut Suppresses Up-Regulation of AKT to Inhibit Proliferation and Migration of VSMCs}

AKT is essential for vascular smooth muscle cell (VSMC) proliferation and migration. Ablation of AKT caused severe atherosclerotic plaques (Fernandez and Ljenkins, 2009). Using MTT and transwell chamber assays, Ang II-induced VSMC proliferation and migration were inhibited, and the levels of p-AKT (308) and p-AKT (473) levels were decreased in the Lut group compared to the Ang II group. These findings strongly suggest that Lut down-regulates the AKT signaling pathway and inhibits the proliferation and migration of VSMCs (Jiang et al., 2013; Xu et al., 2015).

\section{Binding of Lut at the ATP-Binding Pockets of Src Kinase Suppresses Inflammatory Response}

The Src kinase signaling pathway is involved in the progression of AS in VSMC proliferation and migration. It also participates 


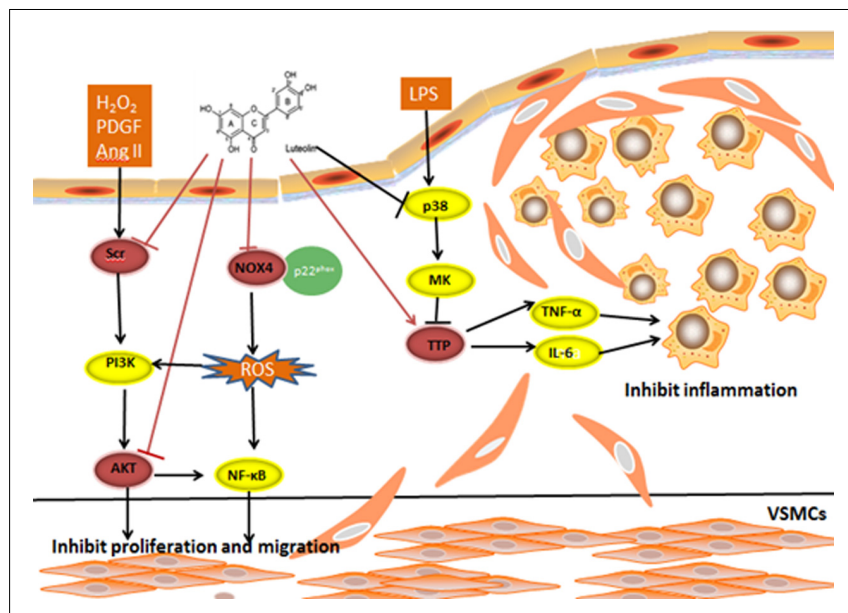

FIGURE $4 \mid \mathrm{H}_{2} \mathrm{O}_{2}$, PDGF, and Angll are stimuli for VSMC proliferation and migration. An inhibitory effect on the Ang II-induced VSMC proliferation and migration rate was observed following pretreatment with Lut. Lut decreases p-AKT (308) and p-AKT (473) expression to inhibit VSMC proliferation and migration. Lut blocks $\mathrm{H}_{2} \mathrm{O}_{2}$-triggered SRC phosphorylation. ATP-binding pocket may be the Lut-binding site in SRC. Lut affects the TNF- $\alpha$ and IL-6 mRNA stability from inhibiting the p38 and MK2 phosphorylation levels by promoting TTP expression. The mRNA stability is known to impact inflammatory processes by regulating inflammatory gene expression. Lut suppresses TNF- $\alpha$-activated ROS generation, and decreases the NOX4 and p22 ${ }^{\text {phox }}$ expression as well as attenuates oxidative stress through the NOX4/ROS-NF-kB pathways.

in reactive oxygen species (ROS)-induced pathophysiological processes of VSMCs. $\mathrm{H}_{2} \mathrm{O}_{2}$ is one type of ROS, which can elicit migration of VSMCs. Lut can block $\mathrm{H}_{2} \mathrm{O}_{2}$-triggered Src phosphorylation. It was shown that activation of Src in the Lut group was significantly lower compared with that of the $\mathrm{H}_{2} \mathrm{O}_{2}$ group. These results indicated that Lut can suppress $\mathrm{H}_{2} \mathrm{O}_{2}$ directed migration and proliferation in VSMCs (Lang et al., 2012). Furthermore, via blockade of Src and Syk, Lut suppressed nuclear translocation of NF- $\mathrm{B}$ but did not suppress other MAPKs. In comparison with wild type and point mutant Src, Lut strongly suppressed the phosphorylation of Src, and ATP could compete with Lut at the ATP-binding pocket of Src. When the concentration of ATP was increased from 400 to $800 \mu \mathrm{g}$, the suppression of Src by Lut was abrogated, suggesting that the ATPbinding pocket may work as a binding site of Lut in Src (Lee et al., 2014).

\section{Lut Participates in TTP-Mediated Regulation of TNF- $\alpha$ and IL- 6 mRNA Stability to Inhibit LPS-Inflammatory Responses in Macrophages}

The pathogenesis of AS is also linked to a chronic inflammatory processes. mRNA stability is known to regulate inflammatory gene expression to impact inflammatory processes ( $\mathrm{Wu}$ and Brewer, 2012). Tristetraprolin (TTP) is regarded as a substrate of p38 MAPK-activated protein kinase 2 (MK2), which can directly target mRNA to the exosome for rapid degradation by binding to adenine-uridine-rich elements (AREs) in the $3^{\prime}$ UTR of target mRNAs (Lai et al., 1999; Shi et al., 2012). A previous study reported that activation of $\mathrm{p} 38 / \mathrm{MK} 2$ pathway can abolish TTPmediated repression of IL- $63^{\prime}$-UTR reporter activity (Zhao et al., 2011). However, it remained elusive whether mRNA stability is involved in the anti-AS mechanism of Lut. Wu W.L. et al. (2013) first found that Lut, in a dose-dependent manner, suppressed the expression of" tumor necrosis factor- $\alpha$ (TNF- $\alpha$ ) and interleukin6 (IL-6) in macrophages. TTP expression was enhanced in the Lut group, but another RNA binding protein, HuR, was not significantly altered. To examine whether Lut affects TNF- $\alpha$ and IL- 6 mRNA stability through TTP activation, we compared the Lut and LPS groups and found that by promoting TTP expression, Lut inhibited the p38 and MK2 phosphorylation level (Wu W.L. et al., 2013).

\section{Lut Attenuates TNF-( $\alpha$-Induced Oxidative Stress through NOX4}

Oxidative stress is regarded as a contributing factor during the AS disease progression. NOX4 is widely expressed in the heart (Ago et al., 2010), and it is the major source of ROS generation (Bedard and Krause, 2007; Sumimoto, 2008). Xia et al. (2014) reported that Lut may be an effective

TABLE 3 | Effect and target effectors of Luteolin in atherosclerosis.

\begin{tabular}{|c|c|c|c|c|c|}
\hline \multirow[t]{2}{*}{ Dose } & \multirow[t]{2}{*}{ Model } & \multirow{2}{*}{$\begin{array}{l}\text { Target } \\
\text { effectors }\end{array}$} & \multicolumn{2}{|c|}{ End points } & \multirow[t]{2}{*}{ Reference } \\
\hline & & & Increase & Decrease & \\
\hline
\end{tabular}

\section{Atherosclerosis}

$50 \mu \mathrm{mol} / \mathrm{l} \quad$ Vascular smooth muscle cells

$50 \mu \mathrm{mol} / \mathrm{l} \quad$ Ang II-stimulated smooth muscle cells

$50 \mu \mathrm{mol} / \mathrm{l} \quad$ Vascular smooth muscle cells

$50 \mu \mathrm{mol} / \mathrm{l} \quad$ Lipopolysaccharide induced inflammatory responses in bone marrow macrophages

$25 \mu \mathrm{mol} /$
Human umbilical vein endothelial cells
AKT

AKT

$\mathrm{SRC}$

TTP

TTP

NOX4
SOD, Intracellular GSH, Bcl-2, IкB- $\alpha$
p-Akt (308), p-Akt (473), PCNA

$\mathrm{SMC}$ proliferation

SMC migration VEGF, NOX4, $p$-Akt

proliferation and, migration $p$-Src, $p$-PDK1, $p$-Akt(308), p-Akt(473)

TNF- $\alpha$, IL-6, $p-\mathrm{P} 38, p-\mathrm{MK} 2$

LDH, ROS, Nox4, p22 ${ }^{\text {phox }}$, Caspase-3, Caspase-9, ICAM-1, VCAM-1, p-NF-кB/p65, p-p38, $p$-ERK1/2
Xu et al., 2015

Ding et al., 2014

Lang et al., 2012

Wu W.L. et al., 2013

Xia et al., 2014 
agent for preventing AS by protecting ECs from TNF$\alpha$-induced inflammatory responses and oxidative damage. They found that Lut suppressed TNF- $\alpha$-induced ROS generation, and it decreased NOX4, p22 phox expression. In turn, downregulated NOX4 reduced the expression of BCL-2, ICAM-1, and VCAM-1. They proposed the formation of a ternary complex involving NOX4 and ROS with NF-кB that regulated TNF$\alpha$-induced oxidative stress. This hypothesis was based on the following evidences: upon exposure to TNF- $\alpha$ in ECs, NF- $\kappa B$ inhibitor pyrrolidinedithiocarbamic acid (PDTC) inhibited Nox4 expression, while Nox inhibitor diphenyleneiodonium (DPI) deceased NF- $\kappa \mathrm{B}$ activation. Moreover, the DCF-detected ROS fluorescence intensity induced by TNF- $\alpha$ are both attenuated by PDTC and DPI. However, the interactions between and structures of the three constituents are needed to be confirmed in the further (Xia et al., 2014).

Anti-atherosclerosis properties of Lut are shown in Table 3. Lut inhibits the proliferation and migration of VSMCs by regulating $\mathrm{AKT}$ and $\mathrm{Src}$, and decreases inflammation and oxidative damage through TTP activation related to mRNA stability and NOX4/ROS-NF- $\mathrm{B}$ pathways. Inflammation and oxidative stress are the main accelerating factors of AS. As the capacities of Lut may be applied to prevent cardiovascular system from AS formation, especially in the early stage of AS or unstable plaques, well-designed studies are needed to explore therapeutic effects of Lut in different stages of AS and different types of plaques.

\section{CONCLUSION AND PERSPECTIVE}

A number of current studies seek to explore ways to reduce the incidence of CVD and improve the therapeutic effectiveness. This review summarizes the molecular mechanisms and cardiovascular effects of Lut and its role in HF, I/R injury, and AS. Lut alleviates cardiomyocyte apoptosis and blocks oxidative stress, all of which promote cytoprotection and reduce I/R injury. The data sets reviewed also provide evidence that Lut improves heart function by enhancing contractility, upregulating autophagy, and preventing cardiac fibrosis. The antiatherosclerosis properties of Lut stems from inhibiting the proliferation and migration of VSMCs, decreasing inflammation and ameliorating oxidative damage. Overall, Lut, which is a ubiquitous dietary flavonoid, is efficacious in cardiovascular protection, and shows promise as a preventive and treatment option for CVD.

\section{REFERENCES}

Ago, T., Kuroda, J., Pain, J., Fu, C., Li, H., and Sadoshima, J. (2010). Upregulation of Nox4 by hypertrophic stimuli promotes apoptosis and mitochondrial dysfunction in cardiac myocytes. Circ. Res. 106, 1253-1264. doi: 10.1161/ CIRCRESAHA.109.213116

Bedard, K., and Krause, K. H. (2007). The NOX family of ROS-generating NADPH oxidases: physiology and pathophysiology. Physiol. Rev. 87, 245-313. doi: 10. 1152/physrev.00044.2005
Although multiple mechanisms of the protective function of Lut on the heart have been addressed, limitations exist in the following aspects. First, previous studies mainly focused on basic research. Therefore, we lack large clinical trials designed to explore the clinical utilization of Lut, especially on the effective therapeutic dosage, and the safety of long-term administration. Based on the evidences of dosages in observational clinical trials or experimental animal studies, the human dietary intake of Lut appears to be much smaller than that used for rodent experimental studies, this result implies that intake of Lut from food may work as a preventative method for CVD, while this intake is insufficient to be an treatment dosage of CVD. Therefore, well-designed prospective clinical trials to observe the effective therapeutic dosages of Lut on patients with myocardium I/R injury, HF, and AS would greatly advance knowledge on its clinical application. In an open-label pilot study, Lut effectively reduced autism spectrum disorders symptoms on behavior in children, which was based on the antioxidant, anti-inflammatory, and neuroprotective effects of Lut. Major adverse effects had not been observed in children who took $10 \mathrm{mg} / \mathrm{kg}$ of Lut (ClinicalTrials.gov identifier: NCT01847521) (Taliou et al., 2013). Although it is not a cardiovascular clinical research, $10 \mathrm{mg} / \mathrm{kg}$ may be used as a reference dosage of safety in future CVD trials. Second, in-depth studies of mechanism need to focus on the synthetic function of Lut on its target effectors and signaling pathways. Further in vitro and in vivo studies should aim to identify the relationship and interaction of these effectors. We hope this review generates the scientific awareness and interest in Lut and provokes that further research by scientists from different fields would boost understanding of the molecular functions of Lut. In conclusion, extensive studies in this area are needed, and appreciation of the molecular mechanisms of Lut may pave the way for development of Lut-based therapeutic agents for CVD.

\section{AUTHOR CONTRIBUTIONS}

DL and YL outlined the review. YL drafted the manuscript. YL and PS edited and reviewed the manuscript. DL, YL, and PS re-reviewed it and all authors approved it.

\section{FUNDING}

This review was supported by National Natural Science Foundation of China (81570326 and 81341009).

Bogoyevitch, M. A., Gillespiebrown, J., Ketterman, A. J., Fuller, S. J., Benlevy, R., Ashworth, A., et al. (1996). Stimulation of the stress-activated mitogen-activated protein kinase subfamilies in perfused heart. p38/RK mitogen-activated protein kinases and c-Jun $\mathrm{N}$-terminal kinases are activated by ischemia/reperfusion. Circ. Res. 79, 162-173. doi: 10.1161/01.RES.79. 2.162

Braunwald, E. (2015). The war against heart failure: the Lancet lecture. Lancet 385, 812-824. doi: 10.1016/S0140-6736(14) $61889-4$ 
Brazil, D. P., Yang, Z.-Z., and Hemmings, B. A. (2004). Advances in protein kinase B signalling: AKTion on multiple fronts. Trends Biochem. Sci. 29, 233-242. doi: 10.1016/j.tibs.2004.03.006

Cabadés, A., Valencia, J., Rueda, J., Echánove, I., Sanjuán, R., Cebrián, J., et al. (2010). Evolution in the management of acute myocardial infarction in the autonomous community of Valencia (Spain): ten years of the primvac registry (1995-2004). Int. J. Biomed. Sci. 6, 87-95.

Chen, C. Y., Peng, W. H., Wu, L. C., Wu, C. C., and Hsu, S. L. (2010). Luteolin ameliorates experimental lung fibrosis both in vivo and in vitro: implications for therapy of lung fibrosis. J. Agric. Food Chem. 58, 11653-11661. doi: 10.1021/ jf1031668

Cheng, H. Y., Hsieh, M. T., Tsai, F. S., Wu, C. R., Chiu, C. S., Lee, M. M., et al. (2010). Neuroprotective effect of luteolin on amyloid beta protein (25-35)induced toxicity in cultured rat cortical neurons. Phytother. Res. 24(Suppl. 1), S102-S108. doi: 10.1002/ptr.2940

Cheng, W. Y., Chiao, M. T., Liang, Y. J., Yang, Y. C., Shen, C. C., and Yang, C. Y. (2013). Luteolin inhibits migration of human glioblastoma U-87 MG and T98G cells through downregulation of Cdc42 expression and PI3K/AKT activity. Mol. Biol. Rep. 40, 5315-5326. doi: 10.1007/s11033-013-2632-1

Cohn, J. N., Ferrari, R., and Sharpe, N. (2000). Cardiac remodeling-concepts and clinical implications: a consensus paper from an international forum on cardiac remodeling. Behalf of an international forum on cardiac remodeling. J. Am. Coll. Cardiol. 35, 569-582. doi: 10.1016/S0735-1097(99)00630-0

Ding, H., Li, D., Zhang, Y., Zhang, T., Zhu, H., Xu, T., et al. (2014). Luteolin inhibits smooth muscle cell migration and proliferation by attenuating the production of Nox4, p-Akt and VEGF in endothelial cells. Curr. Pharm. Biotechnol. 14, 1009-1015. doi: 10.2174/1389201015666140113113843

Domitrovic', R., Jakovac, H., Tomac, J., and Šain, I. (2009). Liver fibrosis in mice induced by carbon tetrachloride and its reversion by luteolin. Toxicol. Appl. Pharmacol. 241, 311-321. doi: 10.1016/j.taap.2009.09.001

Fang, F., Li, D. Y., Pan, H. J., Chen, D., Qi, L. L., Zhang, R. Q., et al. (2011). Luteolin inhibits apoptosis and improves cardiomyocyte contractile function through the PI3K/Akt pathway in simulated ischemia/reperfusion. Pharmacology 88, 149-158. doi: 10.1159/000330068

Fernandez, H. C., and Ljenkins, J. (2009). Absence of Akt1 reduces vascular smooth muscle cell migration and survival and induces features of plaque vulnerability and cardiac dysfunction during atherosclerosis. Arterioscler. Thromb. Vasc. Biol. 29, 2033-2040. doi: 10.1161/ATVBAHA.109.196394

Gustafsson, A. B., and Gottlieb, R. A. (2009). Autophagy in ischemic heart disease. Circ. Res. 104, 150-158. doi: 10.1161/CIRCRESAHA.108.187427

Ha, T., Hua, F., Liu, X., Ma, J., McMullen, J. R., Shioi, T., et al. (2008). Lipopolysaccharide-induced myocardial protection against ischaemia/reperfusion injury is mediated through a PI3K/Akt-dependent mechanism. Cardiovasc. Res. 78, 546-553. doi: 10.1093/cvr/cvn037

Hertog, M. G., Feskens, E. J., Hollman, P. C., Katan, M. B., and Kromhout, D. (1993). Dietary antioxidant flavonoids and risk of coronary heart disease: the Zutphen Elderly Study. Lancet 342, 1007-1011. doi: 10.1016/0140-6736(93) 92876-U

Hertog, M. G. L., Hollman, P. C. H., and Katan, M. B. (1992). Content of potentially anticarcinogenic flavonoids of 28 vegetables and 9 fruits commonly consumed in The Netherlands. J. Agric. Food Chem. 40, 2379-2383. doi: 10. 1021/jf00024a011

Hu, F., Zhai, N., Gao, W., Wu, P., Luo, Y., Pan, D., et al. (2016). Outer balloon ligation increases success rate of ischemia-reperfusion injury model in mice. PLOS ONE 11:e0167631. doi: 10.1371/journal.pone.0167631

Hu, J., Man, W., Shen, M., Zhang, M., Lin, J., Wang, T., et al. (2016). Luteolin alleviates post-infarction cardiac dysfunction by up-regulating autophagy through Mst1 inhibition. J. Cell Mol. Med. 20, 147-156. doi: 10.1111/jcmm. 12714

Hu, W., Xu, T., Wu, P., Pan, D., Chen, J., Chen, J., et al. (2017). Luteolin improves cardiac dysfunction in heart failure rats by regulating sarcoplasmic reticulum $\mathrm{Ca}^{2+}$-ATPase 2a. Sci. Rep. 7:41017. doi: 10.1038/srep41017

Jiang, D., Li, D., and Wu, W. (2013). Inhibitory effects and mechanisms of luteolin on proliferation and migration of vascular smooth muscle cells. Nutrients 5 , 1648-1659. doi: 10.3390/nu5051648

Kho, C., Lee, A., Jeong, D., Oh, J. G., Chaanine, A. H., Kizana, E., et al. (2011). SUMO1-dependent modulation of SERCA2a in heart failure. Nature 477, 601-605. doi: 10.1038/nature10407
Kim, S., Chin, Y. W., and Cho, J. (2017). Protection of cultured cortical neurons by luteolin against oxidative damage through inhibition of apoptosis and induction of heme oxygenase-1. Biol. Pharm Bull. 40, 256-265. doi: 10.1248/ bpb.b16-00579

Kritas, S. K., Saggini, A., Varvara, G., Murmura, G., Caraffa, A., Antinolfi, P., et al. (2013). Luteolin inhibits mast cell-mediated allergic inflammation. J. Biol. Regul. Homeost. Agents 27, 955-959.

Kumphune, S., Chattipakorn, S., and Chattipakorn, N. (2012). Role of p38 inhibition in cardiac ischemia/reperfusion injury. Eur. J. Clin. Pharmacol. 68, 513-524. doi: 10.1007/s00228-011-1193-2

Lai, W. S., Carballo, E., Strum, J. R., Kennington, E. A., Phillips, R. S., and Blackshear, P. J. (1999). Evidence that tristetraprolin binds to AU-rich elements and promotes the deadenylation and destabilization of tumor necrosis factor alpha mRNA. Mol. Cell. Biol. 19, 4311-4323. doi: 10.1128/MCB.19.6. 4311

Lang, Y. S., Chen, D., Li, D. Y., Zhu, M. Y., Xu, T. D., Zhang, T., et al. (2012). Luteolin inhibited hydrogen peroxide-induced vascular smooth muscle cells proliferation and migration by suppressing the Src and Akt signalling pathways. J. Pharm. Pharmacol. 64, 597-603. doi: 10.1111/j.2042-7158.2011. 01438.x

Lee, J. O., Jeong, D., Kim, M. Y., and Cho, J. Y. (2014). ATP-binding pockettargeted suppression of Src and Syk by luteolin contributes to its antiinflammatory action. Mediators Inflamm. 2015:967053. doi: 10.1155/2015/ 967053

Liao, P.-H., Hung, L.-M., Chen, Y.-H., Kuan, Y.-H., Zhang, F. B.-Y., Lin, R.-H., et al. (2011). Cardioprotective effects of luteolin during ischemia-reperfusion injury in rats. Circ. J. 75, 443-450. doi: 10.1253/circj.CJ-10-0381

Lopez-Lazaro, M. (2009). Distribution and biological activities of the flavonoid luteolin. Mini Rev. Med. Chem. 9, 31-59. doi: 10.2174/138955709787001712

Marijan-Jankovic, N. (1957). Effect of luteolin on the heart \& vascular system in animals. Arzneimittelforschung 7, 442-445.

Moran, A. E., Forouzanfar, M. H., Roth, G. A., Mensah, G. A., Ezzati, M., Murray, C. J., et al. (2013). Temporal trends in ischemic heart disease mortality in 21 world regions, 1980 to 2010: the Global Burden of Disease 2010 study. Circulation 61, 1483-1492. doi: 10.1161/CIRCULATIONAHA.113. 004042

Motohashi, H., and Yamamoto, M. (2004). Nrf2-Keap1 defines a physiologically important stress response mechanism. Trends Mol. Med. 10, 549-557. doi: 10.1016/j.molmed.2004.09.003

Nai, C., Xuan, H., Zhang, Y., Shen, M., Xu, T., Pan, D., et al. (2015). Luteolin exerts cardioprotective effects through improving sarcoplasmic reticulum $\mathrm{Ca}^{2+}$-ATPase activity in rats during ischemia/reperfusion in vivo. Evid. Based Complement. Alternat. Med. 2015:365854. doi: 10.1155/2015/365854

Nakayama, A., Morita, H., Nakao, T., Yamaguchi, T., Sumida, T., Ikeda, Y., et al. (2015). A food-derived flavonoid luteolin protects against angiotensin II-induced cardiac remodeling. PLOS ONE 10:e0137106. doi: 10.1371/journal. pone. 0137106

Pinton, P., Giorgi, C., Siviero, R., Zecchini, E., and Rizzuto, R. (2008). Calcium and apoptosis: ER-mitochondria $\mathrm{Ca}^{2+}$ transfer in the control of apoptosis. Oncogene 27, 6407-6418. doi: 10.1038/onc.2008.308

Hansson, G. K. (2005). Mechanisms of disease: inflammation, atherosclerosis, and coronary artery disease. N. Engl. J. Med. 352, 1626-1695. doi: 10.1056/ NEJMra043430

Qi, L., Pan, H., Li, D., Fang, F., Chen, D., and Sun, H. (2011). Luteolin improves contractile function and attenuates apoptosis following ischemia-reperfusion in adult rat cardiomyocytes. Eur. J. Pharmacol. 668, 201-207. doi: 10.1016/j.ejphar. 2011.06.020

Rosenkranz, S. (2004). TGF- $\beta 1$ and angiotensin networking in cardiac remodeling. Cardiovasc. Res. 63, 423-432. doi: 10.1016/j.cardiores.2004.04.030

Schüssler, M., Hölzl, J., and Fricke, U. (1995). Myocardial effects of flavonoids from Crataegus species. Arzneimittelforschung 45, 842-845.

Shi, J. X., Su, X., Xu, J., Zhang, W. Y., and Shi, Y. (2012). MK2 posttranscriptionally regulates TNF- $\alpha$-induced expression of ICAM- 1 and IL- 8 via tristetraprolin in human pulmonary microvascular endothelial cells. Am. J. Physiol. Lung Cell. Mol. Physiol. 302, L793-L799. doi: 10.1152/ajplung.00339.2011

Si, H., Wyeth, R. P., and Liu, D. (2014). The flavonoid luteolin induces nitric oxide production and arterial relaxation. Eur. J. Nutr. 53, 269-275. doi: 10.1007/ s00394-013-0525-7 
Somerset, S. M., and Johannot, L. (2008). Dietary flavonoid sources in Australian adults. Nutr. Cancer 60, 442-449. doi: 10.1080/0163558080 2143836

Sumimoto, H. (2008). Structure, regulation and evolution of Nox-family NADPH oxidases that produce reactive oxygen species. FEBS J. 275, 3249-3277. doi: 10.1111/j.1742-4658.2008.06488.x

Sun, D., Huang, J., Zhang, Z., Gao, H., Li, J., Shen, M., et al. (2012). Luteolin limits infarct size and improves cardiac function after myocardium ischemia/reperfusion injury in diabetic rats. PLOS ONE 7:e33491. doi: 10.1371/ journal.pone.0033491

Sun, D. W., Zhang, H. D., Mao, L., Mao, C. F., Chen, W., Cui, M., et al. (2015). Luteolin inhibits breast cancer development and progression in vitro and in vivo by suppressing notch signaling and regulating MiRNAs. Cell. Physiol. Biochem. 37, 1693-1711. doi: 10.1159/000438535

Sun, G.-B., Sun, X., Wang, M., Ye, J.-X., Si, J.-Y., Xu, H.-B., et al. (2012). Oxidative stress suppression by luteolin-induced heme oxygenase-1 expression. Toxicol. Appl. Pharmacol. 265, 229-240. doi: 10.1016/j.taap.2012.10.002

Takemura, G., Miyata, S., Kawase, Y., Okada, H., Maruyama, R., and Fujiwara, H. (2006). Autophagic degeneration and death of cardiomyocytes in heart failure. Autophagy 2, 212-214. doi: 10.4161/auto.2608

Taliou, A., Zintzaras, E., Lykouras, L., and Francis, K. (2013). An open-label pilot study of a formulation containing the anti-inflammatory flavonoid luteolin and its effects on behavior in children with autism spectrum disorders. Clin. Ther. 35, 592-602. doi: 10.1016/j.clinthera.2013.04.006

Tilemann, L., Lee, A., Ishikawa, K., Aguero, J., Rapti, K., Santos-Gallego, C., et al. (2013). SUMO-1 gene transfer improves cardiac function in a large-animal model of heart failure. Sci. Transl. Med. 5, 211ra159. doi: 10.1126/scitranslmed. 3006487

Wang, F., Li, D. Y., Chen, J., Hu, W. J., and Liu, Y. (2013). Heart protective effects of luteolin on rats with doxorubicin-induced heart failure. Latin Am. J. Pharm. 32, 1313-1320.

Wang, G., Li, W., Lu, X., Bao, P., and Zhao, X. (2012). Luteolin ameliorates cardiac failure in type I diabetic cardiomyopathy. J. Diabetes Complications 26, 259-265. doi: 10.1016/j.jdiacomp.2012.04.007

Wang, L., Lee, I. M., Zhang, S. M., Blumberg, J. B., Buring, J. E., and Sesso, H. D. (2009). Dietary intake of selected flavonols, flavones, and flavonoid-rich foods and risk of cancer in middle-aged and older women. Am. J. Clin. Nutr. 89, 905-912. doi: 10.3945/ajcn.2008.26913

Weng, C. J., and Yen, G. C. (2012). Flavonoids, a ubiquitous dietary phenolic subclass, exert extensive in vitro anti-invasive and in vivo anti-metastatic activities. Cancer Metastasis Rev. 31, 323-351. doi: 10.1007/s10555-0129347-y

Werner, C. M., and Böhm, M. (2008). The therapeutic role of RAS blockade in chronic heart failure. Ther. Adv. Cardiovasc. Dis. 2, 167-177. doi: 10.1177/ 1753944708091777

Wu, W. L., Li, D. Y., Zong, Y., Zhu, H., Pan, D. F., Xu, T. D., et al. (2013). Luteolin inhibits inflammatory responses via p38/MK2/TTP-mediated mRNA stability. Molecules 18, 8083-8094. doi: 10.3390/molecules 18078083

Wu, X., Xu, T. D., Li, D. Y., Zhu, S. S., Chen, Q. P., Hu, W. J., et al. (2013). ERK/PP1a/PLB/SERCA2a and JNK pathways are involved in luteolin-mediated protection of rat hearts and cardiomyocytes following ischemia/reperfusion. PLOS ONE 8:e82957. doi: 10.1371/journal.pone. 0082957

$\mathrm{Wu}, \mathrm{X}$., and Brewer, G. (2012). The regulation of mRNA stability in mammalian cells: 2.0. Gene 500, 10-21. doi: 10.1016/j.gene.2012.03.021
Xia, F., Wang, C., Jin, Y., Liu, Q., Meng, Q., Liu, K., et al. (2014). Luteolin protects HUVECs from TNF- $\alpha$-induced oxidative stress and inflammation via its effects on the Nox4/ROS-NF-кB and MAPK pathways. J. Atheroscler. Thromb. 21, 768-783. doi: 10.5551/jat.23697

Xu, T. D., Zhu, H., Li, D. Y., Lang, Y. S., Cao, L. J., Liu, Y., et al. (2015). Luteolin inhibits angiotensin II-stimulated VSMC proliferation and migration through downregulation of Akt phosphorylation. Evid. Based Complement. Alternat. Med. 2015:931782. doi: 10.1155/2015/931782

Yan, L., Vatner, D. E., Kim, S. J., Ge, H., Masurekar, M., Massover, W. H., et al. (2005). Autophagy in chronically ischemic myocardium. Proc. Natl. Acad. Sci. U.S.A. 102, 13807-13812. doi: 10.1073/pnas.0506843102

Yang, J. T., Qian, L. B., Zhang, F. J., Wang, J., Ai, H., Tang, L. H., et al. (2014). Cardioprotective effects of luteolin on ischemia/reperfusion injury in diabetic rats are modulated by eNOS and the mitochondrial permeability transition pathway. J. Cardiovasc. Pharmacol. 65:349. doi: 10.1097/FJC. 0000000000000202

Yu, D., Li, M., Tian, Y., Liu, J., and Shang, J. (2015). Luteolin inhibits ROS-activated MAPK pathway in myocardial ischemia/reperfusion injury. Life Sci. 122, 15-25. doi: 10.1016/j.lfs.2014.11.014

Zhang, B. C., Zhang, C. W., Wang, C., Pan, D. F., Xu, T. D., and Li, D. Y. (2016). Luteolin attenuates foam cell formation and apoptosis in Ox-LDL-stimulated macrophages by enhancing autophagy. Cell. Physiol. Biochem. 39, 2065-2076. doi: 10.1159/000447902

Zhang, W., Chen, X. F., Huang, Y. J., Chen, Q. Q., Bao, Y. J., and Zhu, W. (2012). 2,3,4,5-Tetrahydroxystilbene-2-O-beta-D-glucoside inhibits angiotensin IIinduced cardiac fibroblast proliferation via suppression of the reactive oxygen species-extracellular signal-regulated kinase 1/2 pathway. Clin. Exp. Pharmacol. Physiol. 39, 429-437. doi: 10.1111/j.1440-1681.2012.05692.x

Zhang, Y. C., Gan, F. F., Shelar, S. B., Ng, K. Y., and Chew, E. H. (2013). Antioxidant and Nrf2 inducing activities of luteolin, a flavonoid constituent in Ixeris sonchifolia Hance, provide neuroprotective effects against ischemia-induced cellular injury. Food Chem. Toxicol. 59, 272-280. doi: 10.1016/j.fct.2013.05.058

Zhao, W., Liu, M., D'silva, N. J., and Kirkwood, K. L. (2011). Tristetraprolin regulates interleukin-6 expression through p38 MAPK-dependent affinity changes with mRNA $3^{\prime}$ untranslated region. J. Interferon Cytokine Res. 31, 629-637. doi: 10.1089/jir.2010.0154

Zhu, S., Xu, T., Luo, Y., Zhang, Y., Xuan, H., Ma, Y., et al. (2017). Luteolin enhances sarcoplasmic reticulum $\mathrm{Ca}^{2+}$-ATPase activity through p38 MAPK signaling thus improving rat cardiac function after ischemia/reperfusion. Cell Physiol. Biochem. 41, 999-1010. doi: 10.1159/000460837

Zsebo, K., Yaroshinsky, A., Rudy, J. J., Wagner, K., Greenberg, B., Jessup, M., et al. (2014). Long-term effects of AAV1/SERCA2a gene transfer in patients with severe heart failure: analysis of recurrent cardiovascular events and mortality. Circ. Res. 114, 101-108. doi: 10.1161/CIRCRESAHA.113.302421

Conflict of Interest Statement: The authors declare that the research was conducted in the absence of any commercial or financial relationships that could be construed as a potential conflict of interest.

Copyright (c) 2017 Luo, Shang and Li. This is an open-access article distributed under the terms of the Creative Commons Attribution License (CC BY). The use, distribution or reproduction in other forums is permitted, provided the original author(s) or licensor are credited and that the original publication in this journal is cited, in accordance with accepted academic practice. No use, distribution or reproduction is permitted which does not comply with these terms. 